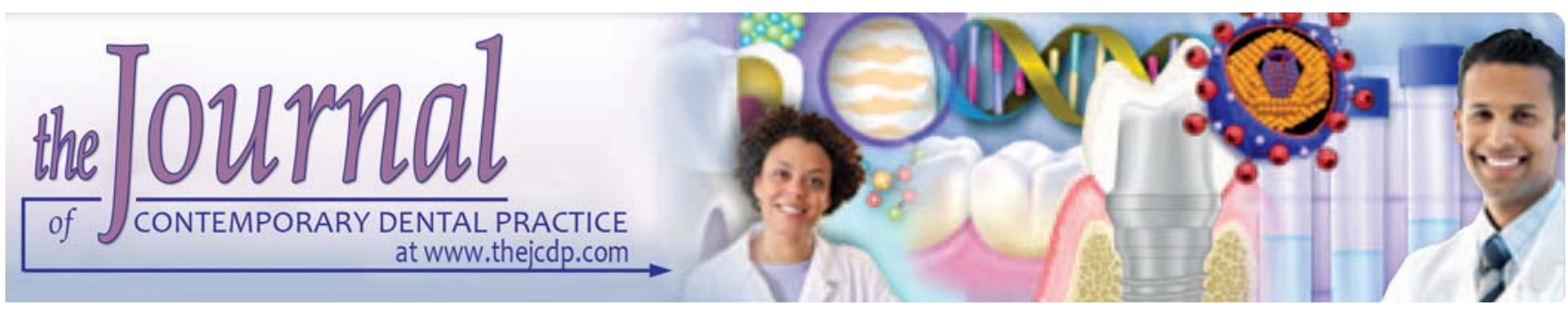

\title{
Periodontal Pathogens and Respiratory Diseases- Evaluating Their Potential Association: A Clinical and Microbiological Study
}

S Vadiraj, Rashmita Nayak, Gopal Krishna Choudhary, Nitin Kudyar, BR Spoorthi

\begin{abstract}
Objective: To evaluate whether any potential association exists between respiratory diseases such as chronic obstructive pulmonary disease (COPD) and periodontal health status clinically and or microbiologically.
\end{abstract}

Materials and methods: Fifty patients of COPD (test group) and 50 Patients without COPD (control group) were recruited for the study with more than 20 years of age with at least six natural teeth. All the patients were nonsmokers. Periodontal health was assessed by measuring clinical attachment loss (CAL) and gingival bleeding by using William's graduated periodontal probe. Microbiological evaluation was done by collecting sputum samples of the subjects with respiratory diseases to find out any periodontal pathogen in the lung fluid.

Result and conclusion: The results showed that the subjects with COPD had significantly more bleeding sites (i.e. $>20 \%$ ) and had more of the clinical mean attachment loss $(2.84 \pm 0.66)$ than those without COPD. On the basis of the observed results of the study, we can hypothesize that the risk for COPD appeared to be significantly elevated when attachment loss was found to be severe.

Clinical significance: It is conceivable that oral interventions that improve oral health status may prove to lower the severity of lung infection in susceptible populations.

Keywords: Periodontal disease, Respiratory disease, Periodontal medicine.

How to cite this article: Vadiraj S, Nayak R, Choudhary GK, Kudyar N, Spoorthi BR. Periodontal Pathogens and Respiratory Diseases_Evaluating Their Potential Association: A Clinical and Microbiological Study. J Contemp Dent Pract 2013;14(4):610-615.

Source of support: Nil

Conflict of interest: None declared

\section{INTRODUCTION}

Recently, there has been resurgence of interest in field of periodontal medicine. We view the term periodontal medicine, as first suggested by Offenbacher ${ }^{1}$ that defines as rapidly emerging branch of periodontology focusing on the wealth of new data establishing a strong relationship between periodontal health or disease and systemic health or disease. Among these interactions, the relation between periodontitis and respiratory diseases has been largely studied. Recent cross-sectional epidemiological studies have suggested a potential association between poor oral health and respiratory diseases, such as pneumonia and chronic obstructive pulmonary disease (COPD). ${ }^{2}$ COPD is a condition in which there is chronic obstruction to airflow with excess production of sputum as a result of chronic bronchitis or emphysema. ${ }^{3}$

The most important established risk factor for COPD is a history of prolonged cigarette smoking. Chronic exposure to toxic atmospheric pollutants may also contribute to the disease. Genetic conditions including a defective alpha 1-antitrypsin gene, variant 1-antichymotrypsin, alpha 2-macroglobulin, vitamin D-binding protein and blood group antigen genes may also predispose subjects to COPD. ${ }^{4}$ Lower respiratory tract infections, including exacerbation of COPD, depend on the initial colonization of microbial pathogens to oral/pharyngeal surfaces. The pathogens are subsequently shed into the salivary secretions, together with oral bacteria, hydrolytic enzymes and proinflammatory cytokines (Fig. 1).

Thus, the contents of this secretion may contaminate and induce alterations of the respiratory epithelium. ${ }^{5}$ Oral bacteria may modulate the adhesion of respiratory pathogens to mucosal surfaces by altering the environment of the upper airway to enhance the potential for respiratory pathogen colonization of the lower respiratory tract. ${ }^{6}$ The resulting inflamed mucosal epithelium may be more susceptible to infection by respiratory pathogen., ${ }^{7,8}$ 


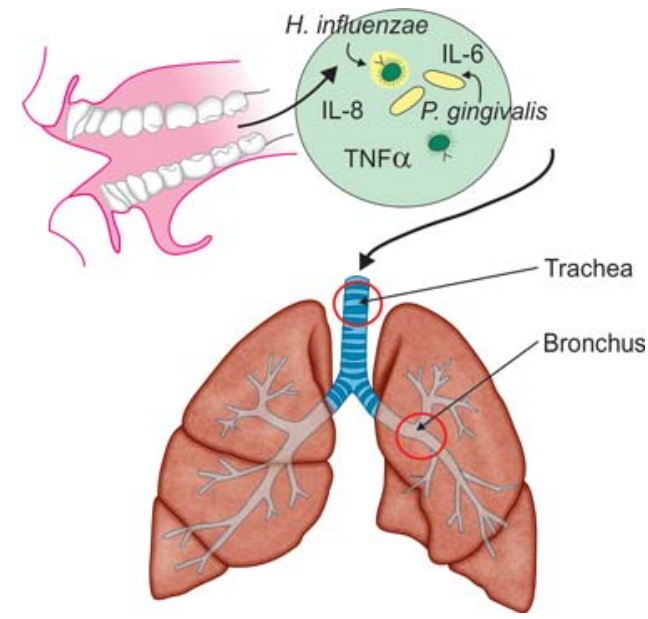

Fig. 1: Bacteria responsible for respiratory diseases and periodontal diseases are shed into the saliva which is then aspirated into the tracheal tree. The cytokines from periodontally diseased sites also enter the tracheal tree where they attract inflammatory responses. (Figures are being reproduced with permission from the American Academy of Periodontology. Source: Role of oral bacteria in respiratory infection. J Periodontol 1999; 70:793-802)

The aim of the present study was to evaluate the potential associations between respiratory diseases and periodontal diseases.

\section{MATERIALS AND METHODS}

This study was carried out in Nijalingappa Medical College and Hospital, Bagalkot, after obtaining the institutions ethical clearance. This cross-sectional retrospective study included a study population of 50 patients of COPD (test group) and 50 patients without COPD (control group) were recruited for the study. All the participants were nonsmokers and were more than 20 years of age with at least six natural teeth. They were randomly selected from the pool of patients who came to the outpatient department. All patients enrolled in the study voluntarily signed an informed consent. A history of bronchitis and/or emphysema was recorded and dichotomized variable (COPD) was also considered.

Periodontal health was assessed by measuring clinical attachment loss (CAL) and gingival bleeding by using William's graduated periodontal probe. Microbiological evaluation was done by collecting Sputum samples of the subjects with respiratory diseases to find out any periodontal pathogen in the lung fluid.

Periodontal disease was measured for determination of:

- Clinical attachment loss (CAL) for each subject was computed and dichotomized as those who had $<2 \mathrm{~mm}$ CAL and those who had $>2 \mathrm{~mm}$ CAL. This cut off was determined by examination of the distribution of MAL for all the teeth examined, where $53.3 \%$ of the subjects had a CAL $<2 \mathrm{~mm}$.
- Gingival bleeding: this was divided as $<20 \%$ of sites that bled on probing and $>20 \%$ of sites that bled on probing. This was done on the basis of the pilot study done before which showed that more than $50 \%$ of the patients had 20\% bleeding sites.

\section{MICROBIOLOGICAL EVALUATION}

Microbiological evaluation was carried out using the sputum samples of the subjects with respiratory diseases to find out any periodontal pathogen in the lung fluid. Sputum sample was collected and transferred to the microbiological laboratory at the medical college. To create an anaerobic environment GasPak ${ }^{\mathrm{TM}} \mathrm{EZ}$ was used.

Principles of the procedure: The GasPak ${ }^{\mathrm{TM}} \mathrm{EZ}$ gas generating pouch systems are single-use systems that produce atmosphere suitable to support the primary isolation and cultivation of anaerobic, microaerophilic or capnophilic bacteria by use of gas generating sachets inside single-use resealable pouches. The GasPak ${ }^{\mathrm{TM}}$ EZ Gas Generating Sachet consists of a reagent sachet containing inorganic carbonate, activated carbon, ascorbic acid and water. When the sachet is removed from the outer wrapper, the sachet becomes activated by exposure to air. The activated reagent sachet and specimens are placed in the GasPak EZ incubation container and it is sealed. The sachet rapidly reduces the oxygen concentration within the container. At the same time, inorganic carbonate produces carbon dioxide. For the cultivation of anaerobic bacteria, the GasPak EZ anaerobe container system sachets produce an anaerobic atmosphere within 2.5 hours, with greater than 15\% carbon dioxide within 24 hours.

Culture: Cultures were grown on blood agar plates in an anaerobic environment, at $95^{\circ} \mathrm{F}\left(35^{\circ} \mathrm{C}\right)$ for at least 48 hours before the plates are examined for growth. Gram staining was performed on the specimen at the time of culture. While infections can be caused by aerobic or anaerobic bacteria or a mixture of both, some infections have a high probability of being caused by anaerobic bacteria.

\section{STATISTICAL ANALYSIS}

The mean and standard deviation values were calculated for all clinical parameters. Chi-square test was used to compare data among the groups and Student t-test. Analysis was done by using SPSS (statistical package for social sciences) version 14.0.

Demographic data of the sample population are summarized in (Table 1). The mean age of subjects with COPD was $48.9 \pm 12.1$ years, while the mean age of controls was $44.0 \pm 9.9$ years. Number of females was less than males both in test and control groups. 


\begin{tabular}{llll}
\multicolumn{3}{c}{ Table 1: Age and sex distribution } \\
\hline \multirow{2}{*}{ No. of cases } & & COPD & Non-COPD \\
& & 50 & 50 \\
\hline \multirow{2}{*}{ Age $(\mathrm{yrs})$} & Range & $25-80$ & $27-64$ \\
SEX & mean \pm SD & $48.9 \pm 12.1$ & $44.0 \pm 9.9$ \\
& MF & 34 & 32 \\
& & 16 & 18 \\
\hline
\end{tabular}

\begin{tabular}{llll}
\multicolumn{5}{c}{ Table 2: Bleeding sites (COPD vs Non-COPD) } \\
$\begin{array}{llll}\text { Sites showing } \\
\text { bleeding of } \%\end{array}$ & COPD N (\%) & $\begin{array}{l}\text { Non-COPD } \\
N(\%)\end{array}$ & Significance \\
\hline$<20 \%$ & $8(16)$ & $34(68)$ & \\
$>20 \%$ & $42(84)$ & $16(32)$ & $* \chi^{2}=27.8$ \\
\hline Total & 50 & 50 & $\mathrm{p}<0.001, \mathrm{HS}$ \\
\hline
\end{tabular}

${ }^{*}$ Chi-square test; HS: highly significant

\begin{tabular}{|c|c|c|c|c|c|c|c|c|c|}
\hline \multirow[t]{2}{*}{ Group } & \multirow[t]{2}{*}{ No. of cases } & \multicolumn{5}{|c|}{ Clinical attachment loss } & \multirow[t]{2}{*}{ Mean $\pm S D$} & \multirow[t]{2}{*}{ Median } & \multirow[t]{2}{*}{ Significance } \\
\hline & & 1.5 & 2.0 & 2.5 & 3.0 & 3.5 & & & \\
\hline COPD & 50 & $8(16)$ & - & $11(22)$ & $16(32)$ & $15(30)$ & $2.84 \pm 0.66$ & 3.0 & ${ }^{* \star} \mathrm{p}<0.001, \mathrm{HS}$ \\
\hline Non-COPD & 50 & $10(20)$ & $10(20)$ & $17(34)$ & $9(18)$ & $4(8)$ & $2.37 \pm 0.60$ & 2.5 & \\
\hline
\end{tabular}

**student t-test; HS: highly significant
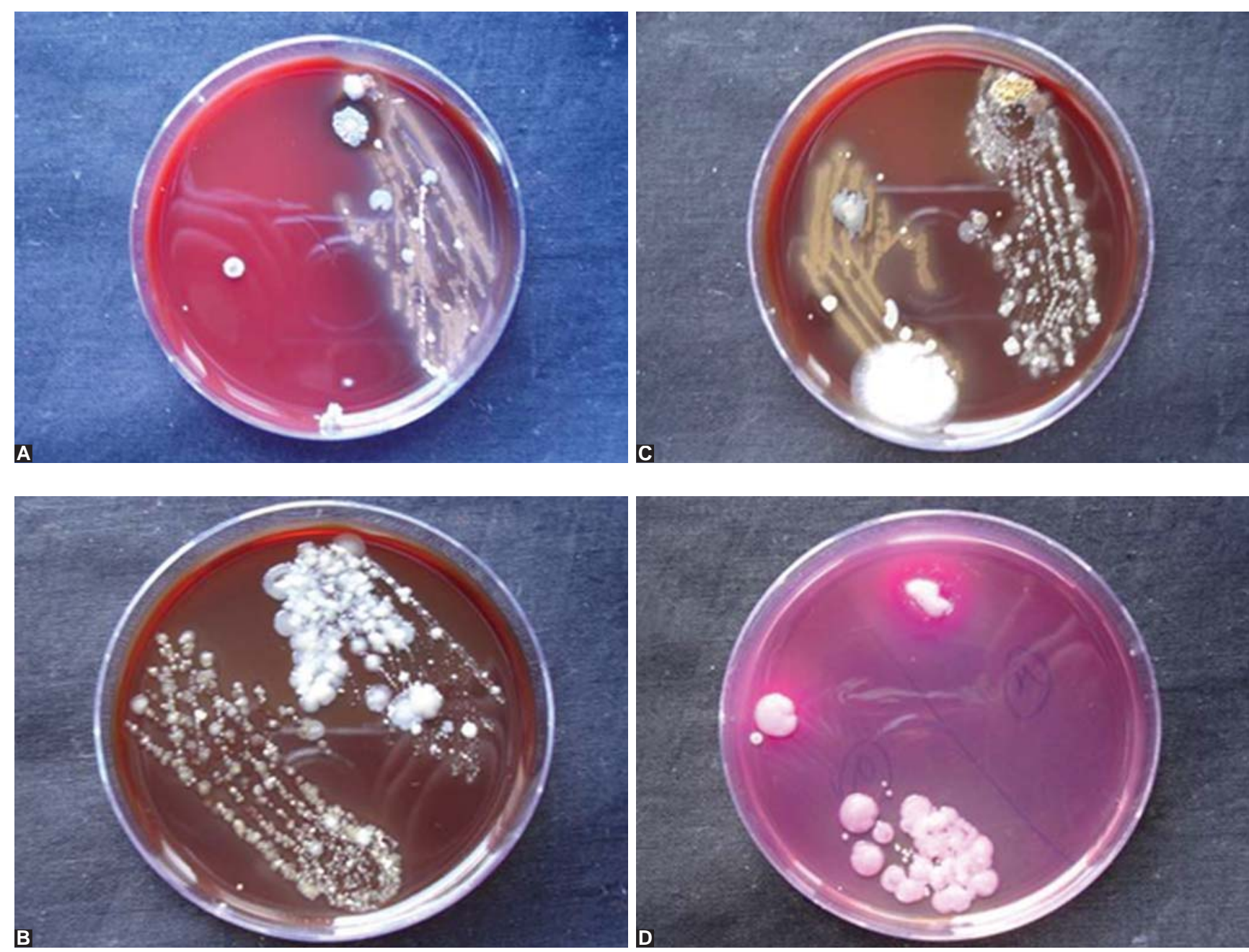

Figs 2A to D: (A) Porphyromonas spp, (B) Staphylococcus, Streptococcus (C) Staphylococcus, Streptococcus (D) Candida 


\section{DISCUSSION}

The findings of the present analysis, together with other recently published studies support an association between poor periodontal health and COPD.

In our study we found that patients with $>20 \%$ of bleeding sites were more in COPD patients (84\%) compared to non-COPD patients (16\%). We also noticed that clinical attachment loss was also more in COPD patients than in non-COPD patients. This may be because of various reasons which include:

1. Aspiration of oral pathogens (such as P. gingivalis, etc.) into the lung.

2. Periodontal disease associated enzymes in saliva may modify mucosal surfaces to promote adhesion and colonization by respiratory pathogen.

3. Periodontal disease associated enzyme may destroy salivary pellicles on pathogenic bacteria.

4. Cytokines originating from periodontal tissues may alter respiratory epithelium to promote infection by respiratory pathogen. ${ }^{5}$
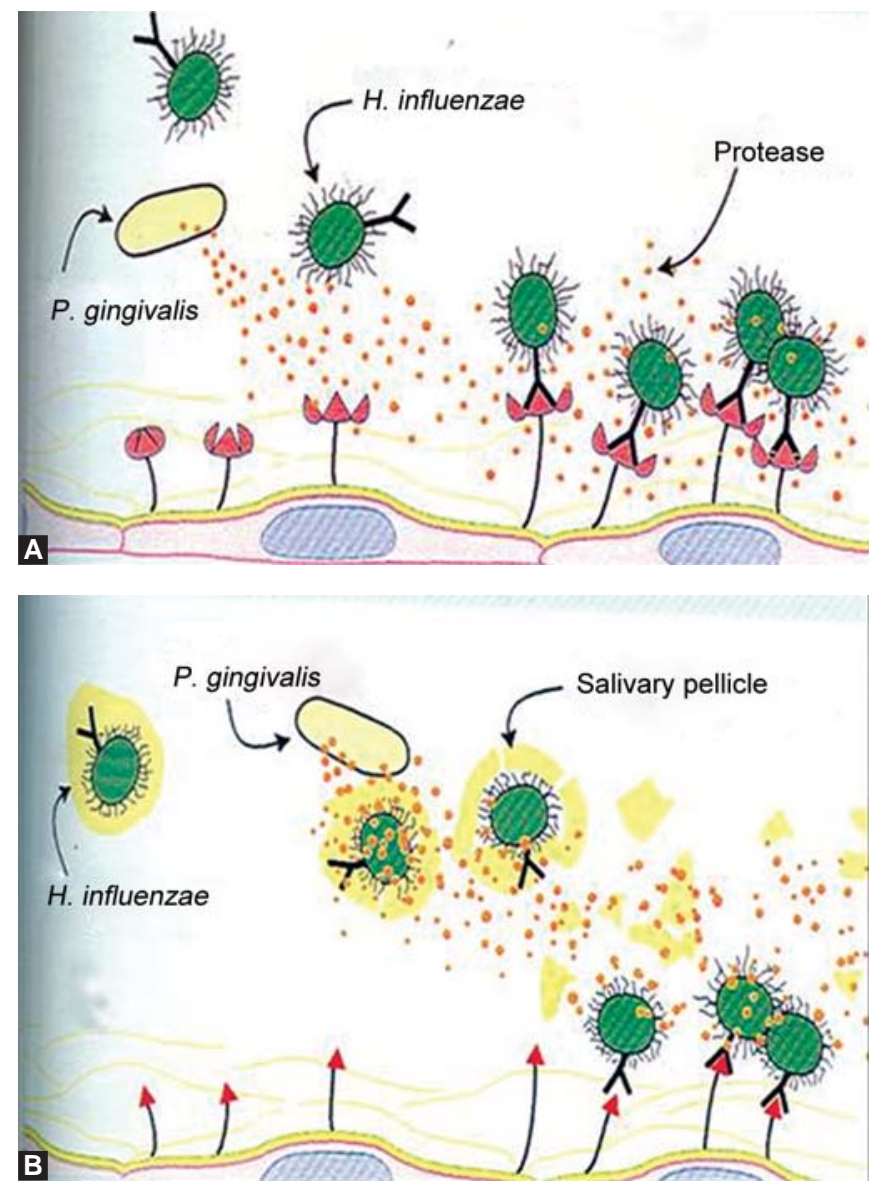

Estimates have been made that $40 \%$ of all cases of aspiration pneumonia, necrotizing pneumonia, lung abscesses, involve anaerobic bacteria. A variety of oral anaerobes and facultative anaerobes have been cultured from infected lung fluids including $P$. gingivalis, Bacteroids gracilus, Bacteroids oralis, Fusobacterium spp. Most, if not all have been implicated in pathogenesis of periodontal diseases. Distal airway of COPD patients frequently shows bacterial colonization by nonpathogenic oral bacteria, including oral Streptococci species. Indeed, Streptococci viridans have been found to be cause of pneumonia in $4 \%$ of the patients. ${ }^{9}$ Several studies have been documented regarding lack of oral health in hospitalized patients. Lack of attention to oral hygiene results in increase in mass and complexity of dental plaque, which will lead to interaction between indigenous plaque bacteria and respiratory pathogens. This will lead to colonization of dental plaque by respiratory pathogen. Dental plaque can therefore provide reservoir for respiratory pathogens which will later shed into saliva. Contamination of distal portion of respiratory tree by this saliva can lead to pulmonary infection.
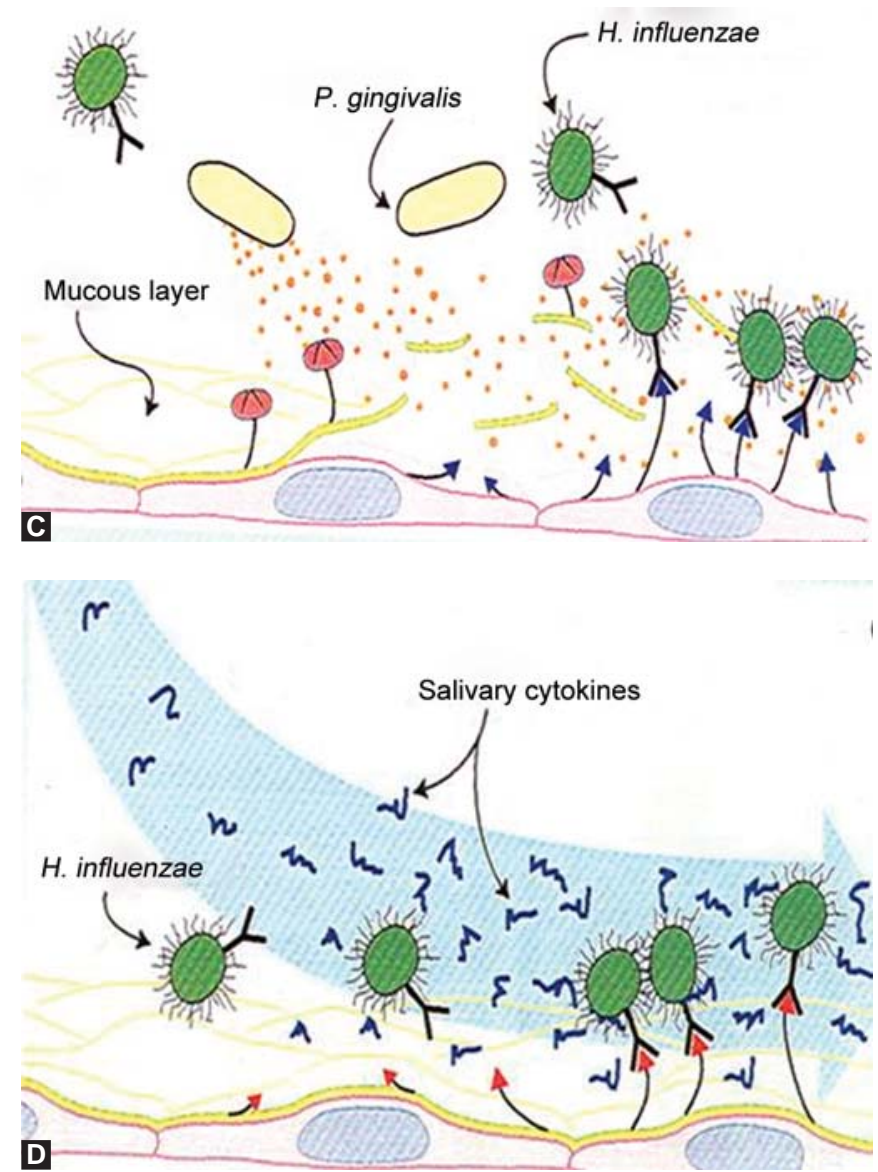

Figs 3A to D: (Figures are being reproduced with permission from the American Academy of Periodontology. Source: Role of oral bacteria in respiratory infection. J Periodontol 1999;70:793-802) (A) Dental pathogens such as $P$. gingivalis produce enzymes (such as proteases) that alter mucosal surface adhesion receptors for respiratory pathogens such as $H$. influenzae, which adhere, colonize and can subsequently be aspirated into lungs to cause infection, (B) Oral bacteria such as $P$. gingivalis produce enzymes that degrade the salivary molecules that normally form pellicle on the pathogens which prevents them from adhering to mucosal surfaces. (C) Oral bacteria produce enzymes that degrade the salivary pellicles on mucosal layer. (D) Cytokines up regulate the expression of adhesion receptors on the mucosal surfaces to promote respiratory pathogen colonization 
Saliva also contains wide variety of hydrolytic enzymes like fibronectin and amount of enzyme activity in saliva is related to the periodontal and oral hygiene status of subjects tested. ${ }^{10}$ A direct relationship has been found between fibronectin and oral hygiene status. ${ }^{11}$ It is conceivable that in subjects having periodontal diseases and elevated level of proteolytic bacteria such as $P$. gingivalis and spirochetes, fibronectin activity may alter the mucosal epithelium to increase the adhesion and colonization of respiratory pathogen (Fig. 3A).

Recent evidence suggests that the respiratory pathogen like $H$. influenzae binds to mucins contained within mucosal secretions. ${ }^{12}$ This binding may involve sialic acid residues. In the context of COPD, it is possible that subjects with poor oral hygiene may have elevated levels of hydrolytic enzymes in their saliva. These enzymes may process mucins which reduce their ability to bind to and clear pathogens such as $H$. influenzae (Fig. 3B).

Conversely enzymes may process the respiratory epithelium to modulate adhesion of such pathogens to mucosal surface (Fig. 3C).

In untreated periodontal diseases, oral pathogens continuously stimulate cells of oral tissues and periodontium to release wide variety of cytokines and other variety of biologically active molecules. ${ }^{13}$ Cytokines produced by these epithelial and connective tissue cells in response to the bacteria include IL- $1 \alpha$, IL-1 $\beta$, IL-6, IL-8 and TNF. In fact, oral Streptococci which are abundant in dental plaque, stimulate the release of high levels of these cytokines from these cells. Epithelial cells also known to alter expression of various cell adhesion molecules on their surface in response to cytokine stimulation. Variation in expression of such adhesion molecules may alter the interaction of bacterial pathogen with the mucosal surface (Fig. 3D).

Data from the National Health and Nutrition Examination Survey I (NHANES I) where 23,808 individuals were analyzed. Of these, 464 individuals reported a suspected respiratory infection. Patients who had the highest oral hygiene index (OHI) values were 4.5 times more likely to have COPD than patients with an $\mathrm{OHI}$ of $0 .{ }^{14}$ Although this study was cross-sectional in design, the result is supported by a longitudinal study performed by Hayes et al. They defined patients with a history of periodontal diseases as assessed by radiographic alveolar bone loss (ABL) and found that $\mathrm{ABL}$ at baseline is an independent risk factor for COPD, and increased ABL is associated with increased risk for COPD. ${ }^{15}$ Although both results are interesting, these data need to be interpreted with caution due to the imprecise definitions of respiratory diseases. Travis described a biologically plausible mechanism to explain the theoretical association between emphysema and periodontal diseases. Both diseases share very similar pathological processes that are characterized by the recruitment of neutrophils to inflammatory sites. Destruction of connective tissue is a common result in both diseases.

To summarize in short, in patients with poor oral hygiene, i.e. with inadequate plaque control and accompanying periodontal disease will lead to pulmonary disease. It should be noted that we are not arguing that poor oral health alone is responsible for COPD. Rather, poor oral health may work in concert with other factors (such as continued smoking, environmental pollutants, viral infections, allergy and/or genetic factors) to promote the progression and/or exacerbation of COPD. Further investigations will establish the role of oral health in the initiation and progression of COPD.

\section{ACKNOWLEDGMENT}

We are thankful to the staff of Department of Periodontology, PMNM Dental College and Hospital, Bagalkot, Karnataka and Department of Microbiology, Medical College, Bagalkot, Karnataka, India for their support.

\section{REFERENCES}

1. Offenbacher S. Periodontal diseases. Pathogenesis. Ann Periodontol 1996;1:821-878.

2. Scannapieco FA, Stewart EM, Mylotte JM. Colonization of dental plaque by respiratory pathogens in medical intensive care patients. Crit Care Med 1992;20:740-745.

3. Ingram RH. Chronic bronchitis, emphysema and airway obstruction. In: Isselbacher KJ, Brounwald E, Wilson JD, Martin JB, Fauci AS, Kasper DL, editors. Harrison's Principles of Internal Medicine, New York: Mcgraw-Hill 1994;1197-1206.

4. Stanford AJ, Weir TD, Pare PD. Genetic risk factors for chronic obstructive pulmonary disease. Eur Resp J 1997;10:1380-1391.

5. Scannapieco FA. Role of oral bacteria in respiratory infection. J Periodontol 1999;70:793-802.

6. Scannapieco FA, Mylotte JM. Relationship between periodontal disease and bacterial pneumonia. J Periodontol 1996;67: 1114-1122.

7. Hedges SR, Agace WW, Svanborg C. Epithelial cytokine responses and mucosal cytokine networks. Trends Microbial 1995;3:266-270.

8. Svanborg C, Hedlund M, Connell H, et al. Bacterial adherence and mucosal cytokine responses. Receptors and transmembrane signaling. Ann NY Acad Sci 1996;797:177-190.

9. Torres A, Dorca J, Zalacain R. Community acquired pneumonia in chronic obstructive pulmonary disease: a Spanish multicenter study. Am J Crit Care Med 1996;154:1456-1461.

10. Nakamura M, Slots J. Origin and relationship to periodontal diseases. J Periodont Res 1983;18:559-569.

11. Gibbons RJ, Etherden I. Fibronectin degrading enzymes in saliva and its relationship to oral cleanliness. J Periodont Res 1986; 21:386-395.

12. Reddy MS, Murphy TF, Faden HS, Berstein JM. Middle ear mucin glycoprotein: purification and interaction with nontypable. Otolaryngol Head Neck Surg 1997;116:175-180. 
13. Reddi K, Wilson M, Nair S, Poole S, Henderson B. Comparison of the proinflammatory cytokine-stimulating activity of the surface associated proteins of periodontopathic bacteria. J Periodont Res 1996;31:120-130.

14. Scannapieco FA, Papandonatos GD, Dunford RG. Associations between oral conditions and respiratory disease in a national sample survey population. Ann Periodontol 1998;3:251-256.

15. Hayes C, Sparrow D, Cohen M, Vokonas PS, Garcia RI. The association between alveolar bone loss and pulmonary function: the VA Dental Longitudinal Study. Ann Periodontol 1998; $3: 257-261$.

\section{ABOUT THE AUTHORS}

\section{S Vadiraj (Corresponding Author)}

Reader, Department of Periodontics, PDU Dental College and Hospital, Solapur, Maharashtra, India, e-mail: vadi24@rediffmail.com

\section{Rashmita Nayak}

Reader, Department of Periodontics, Institute of Dental Sciences Bhubaneshwar, Odisha, India

\section{Gopal Krishna Choudhary}

Reader, Department of Prosthodontics, Institute of Dental Sciences Bhubaneshwar, Odisha, India

\section{Nitin Kudyar}

Senior Lecturer, Department of Periodontics, Indira Gandhi Government Dental College and Hospital Jammu, Jammu and Kashmir, India

\section{BR Spoorthi}

Reader, Department of Oral Pathology, MS Ramaiah Dental College and Hospital, Bengaluru, Karnataka, India 